\title{
Organization Chart
}

National Cancer Institute

\section{Source}

National Cancer Institute. Organization Chart. NCI Thesaurus. Code C18245.

The hierarchy of groups and sub-groups within an organization. 